\title{
Kinematics of the head and associated vertebral artery length changes during high-velocity, low-amplitude cervical spine manipulation
}

Lindsay Gorrell ( $\sim$ lindsaymary.gorrell@uzh.ch )

Balgrist University Hospital: Universitatsklinik Balgrist https://orcid.org/0000-0002-1937-741X

Gregor Kuntze

University of Calgary

Janet L Ronsky

University of Calgary

Ryan Carter

University of Calgary

Bruce Symons

University of Calgary

John J Triano

Canadian Memorial Chiropractic College

Walter Herzog

University of Calgary

Research

Keywords: Cervical spine, Kinematics, Spinal manipulation, Spontaneous vertebral artery dissection, Strain

Posted Date: October 29th, 2021

DOI: https://doi.org/10.21203/rs.3.rs-1016230/v1

License: (c) (i) This work is licensed under a Creative Commons Attribution 4.0 International License. Read Full License 


\section{Abstract \\ Background}

Cervical spine manipulation (CSM) is a frequently used treatment for neck pain. Despite its demonstrated efficacy, concerns regarding CSM safety remain. The purpose of this study was to quantify the angular displacements of the head relative to the sternum and the associated vertebral artery (VA) length changes during the thrust phase of CSM.

\section{Methods}

Bilateral rotation and lateral flexion CSM procedures were delivered from C1 to C7 to three male cadaveric donors. For each CSM the force-time profile was recorded using a thin, flexible pressure pad $(100-200 \mathrm{~Hz})$, to determine the timing of the thrust. Three dimensional displacements of the head relative to the sternum were recorded using an eight-camera motion analysis system $(120-240 \mathrm{~Hz})$ and angular displacements of the head relative to the sternum were computed in Matlab. Positive kinematic values indicate flexion, left lateral flexion, and left rotation. Ipsilateral refers to the same side as the clinician's contact and contralateral, the opposite. Length changes of the VA were recorded using eight piezoelectric ultrasound crystals, inserted along the entire vessel. VA length changes were calculated as $D=\left(L_{1}-L_{0}\right) / L_{0}$, where $L_{0}=$ length of the whole VA (sum of segmental lengths) or the V3 segment at CSM thrust onset; $L_{1}=$ whole VA or V3 length at peak force during the CSM thrust.

\section{Results}

VA length changes during the thrust phase were greatest with ipsilateral rotation CSM (producing contralateral head rotation): [mean \pm SD (range)] whole artery [1.3 $\pm 1.0(-0.4$ to $3.3 \%)$; and V3 segment [2.6 $\pm 3.6(-0.4$ to $11.6 \%)$. For ipsilateral rotation CSM, head angular displacements relative to the sternum during the thrust were: flexion/extension $\left[1.2 \pm 3.4\left(-6.6\right.\right.$ to $\left.\left.7.6^{\circ}\right)\right]$; rotation $\left[-10.2 \pm 3.5\left(-16.1\right.\right.$ to $\left.\left.-3.7^{\circ}\right)\right]$; and lateral flexion [8.8 $\pm 3.0\left(2.5\right.$ to $\left.\left.14.1^{\circ}\right)\right]$.

\section{Conclusion}

Mean head angular displacements and VA length changes were small during CSM thrusts. Of the four different CSM measured, mean VA length changes were largest during rotation procedures. This suggests that if clinicians wish to limit VA length changes, consideration should be given to the type of CSM used.

\section{Introduction}

Neck pain is a common cause of musculoskeletal pain in the adult population, with annual global prevalence estimates in the range of 17 to $75 \%$ and costs in excess of \$US 8 billion/year in the United States alone (1-3). Cervical spine manipulation (CSM) is a frequently used treatment modality for patients with neck pain $(4,5)$ and is recommended in many clinical practice guidelines $(6-8)$. Despite its demonstrated efficacy $(9,10)$, concerns remain surrounding the safety of CSM (11-14). It has been suggested that head and neck extension and rotation during some CSM may stretch and damage the vertebral artery (VA) wall, leading to arterial dissection and stroke $(12,15,16)$. Such damage predominantly occurs in the V3 segment of the artery, which may be vulnerable with elongation (Figure 1), highlighting the importance of investigating length changes in this segment during CSM (17-19).

One approach to investigate the relationship between movement and elongation of the VA during CSM is to quantify the kinematics of the head and associated VA length change. The kinematics of the head relative to the sternum during CSM have been investigated in both asymptomatic live (20-24) and cadaveric subjects $(25,26)$. Despite the use of varying CSM techniques, the current literature reports that head angular displacements during CSM are small, especially for rotation movements (25), and they do not exceed the normal physiological range of motion (21, 23). However, in an early study, angular head displacements were shown to approach the maximal active range of motion for the upper cervical spine at the pre-manipulative position (20). A study by Piper et al. (26) remains the only investigation in which the kinematics of the head relative to the sternum and the associated VA length changes were measured simultaneously. However, in that study, head kinematics and VA length changes at peak CSM force occurrence were reported relative to the VA length and head/neck position in the neutral anatomical position (26). Angular displacements and associated VA length changes during the thrust phase of CSM were not separately reported in that study and therefore remain unknown.

Including the Piper et al. investigation, four studies have quantified the elongation response of the VA to CSM and passive ranges of motion (26-29). In these studies, arterial length changes were reported for specific regions $(26,27)$ or, along the entire course of the artery $(28,29)$ following CSM delivered to a maximum of three vertebral levels. Collectively, it was found that movements involving contralateral head rotation resulted in the largest VA length changes in the V3 segment during both CSM (range: -15 to $18 \%$ ) and passive ranges of motion (0 to 38\%) (26-29). VA length changes measured during CSM were typically lower than those measured during passive range of motion testing and did not approach published failure length changes measured as strains from a neutral anatomical head and neck position (153 to 162\%) (27). Further, on average, the VA must elongate $33.5 \%$ from an arbitrary in-situ position of the head/neck prior to experiencing tensile force (30) and about $12 \%$ when measured from a standardized neutral anatomical position (29).

Despite these reports, the kinematics of the head relative to the sternum and associated VA length changes during the thrust phase of CSM delivered systematically to each level of the cervical spine (C1 to C7) have not been investigated. Therefore, it is unknown if VA length changes differ during the thrust phase with CSM applied to different levels of the cervical spine e.g., upper (C1 \& C2) vs. lower (C3 to C7) vertebra. Furthermore, angular displacements and associated VA length changes during the thrust phase of CSM remain unreported. Therefore, the purpose of this study was to systematically quantify the 
angular displacements of the head relative to the sternum and the associated VA length changes during the thrust phase of two types of CSM (rotation and lateral flexion), applied bilaterally, to each level of the cervical spine (C1 to $\mathrm{C} 7$ ).

\section{Methods}

\section{Donor recruitment and preparation}

Three male cadaveric donors were secured through the University of Calgary's Body Donation Program. The study was approved by the Conjoint Health Research Ethics Board (REB16-0296) of the University of Calgary. Visual inspection revealed no substantial anatomic variations in the origin, course or appearance of the VA. Minor osteophytes were present in the cervical spine of all donors; however, this did not affect the passive ranges of motion of the neck assessed qualitatively prior to dissection. Blunt dissection of the anterior cervical region was performed by a trained anatomist ( 10 years' experience) to expose the VA. All efforts were made to ensure that the minimum amount of tissue was removed to approximate, as closely as possible, the contributions of soft tissues to the neck to movement. VA were instrumented with $2 \mathrm{~mm}$ piezoelectric ultrasound crystals bilaterally (Sonometrics Corporation, London, Canada). Eight crystals were inserted into the lateral aspect of the artery's lumen along its entire length and secured to the arterial wall using three noncollinear sutures (Figure 1). Great care was taken to maintain consistency in crystal spacing (10 to $30 \mathrm{~mm}$ ) and location across all donors. Crystals 1 to 8 were inserted as follows: 1 ) at the mid-point between the subclavian artery and the $\mathrm{C} 6$ transverse foramen; 2 to 5 ) at the mid-point between adjacent transverse foramen of $\mathrm{C} 6$ to $\mathrm{C} 2 ; 6 \&$ 7) adjacent to the $\mathrm{C} 2$ and $\mathrm{C} 1$ transverse foramen respectively and; 8) distal to the $\mathrm{C} 1$ transverse foramen.

There were 2 instances when it was not possible to follow this exact pattern due to normal anatomical variations between donors. Anatomical variations included limited space between adjacent transverse foramen prevented placement of crystals and enlarged cervical nerve roots exiting the neural foramen (31). Following crystal placement, single $3 \mathrm{~mm}$ stainless steel surgical bone pins (IMEX Veterinary Inc, Longview, TX, USA) were introduced into the skull and sternum. Dental cement (Bosworth Company, Skokie, IL, USA) was used to secure the pins with a curing time of at least 10 hours. During this time, all exposed tissues were covered in gauze soaked in a physiological saline solution. Where possible, the duration of dissection and instrumentation ( 16 to 24 hr) was minimized and when no active work was occurring, the specimen was stored at $4^{\circ} \mathrm{C}$ to reduce tissue deterioration. Prior to data collection, prefabricated triads consisting of three non-collinear, $10 \mathrm{~mm}$ diameter retroreflective marker spheres were firmly affixed to each bone pin using quick-setting steel reinforced epoxy (JB Kwik Weld, Sulphur Springs, TX, USA).

\section{Data collection}

Three clinicians (clinical experience 7 to 20 years) performed all CSM. For each donor, data were collected from two clinicians, thus different individuals contributed to the data. The in-situ head position was taken as the arbitrary position that the skull assumed when positioned on the gurney, and was not controlled within or between cadavers. The order of manipulation delivery was random and established using the randomized number generator function in Matlab (vR2019b; Mathworks, USA). Clinicians delivered a single supine, Diversified style (manual, high-velocity low-amplitude) CSM (rotation and lateral flexion) to each cervical vertebra (C1 to $\mathrm{C} 7$ ) on both sides of the neck (32). For all procedures, the articular column of the involved vertebra was targeted through the intact posterior tissues by the antero-lateral aspect of the proximal phalanx of the clinician's second digit. The pre-manipulative position involved head and neck flexion, ipsilateral lateral flexion, and contralateral rotation relative to a neutral anatomical position from the arbitrary head position on the gurney. The pre-manipulative position was defined as the position of the head and neck at the instant of the rapid increase in manipulative force following the relatively steady pre-manipulative force and indicated the onset of the manipulative thrust. From the pre-manipulative position, a rapid, controlled lowamplitude thrust was applied in an intended posterior-anterior (rotation) or medial and slightly inferior (lateral flexion) direction (32).

During each trial, VA length changes were captured using a SonoSoft system (Sonometrics Corporation, London, ON, Canada; 260 to $557 \mathrm{~Hz}$ ) with a spatial resolution of $16 \mu \mathrm{m}$ (27). Prior to, and as necessary throughout data collection, arteries were perfused with ultrasonographic gel to approximate their in-vivo shape and to promote ultrasound signal transmission. For each CSM, the force-time profile was recorded using a thin, flexible pressure pad (Pedar-X, Novel, Munich, Germany; $20 \mathrm{~cm} \times 10 \mathrm{~cm} \times 0.2 \mathrm{~cm}, 100$ to $200 \mathrm{~Hz}$ ), enabling identification of the time of the pre-manipulative position (thrust onset) and peak force (end of the thrust phase) (Figure 2). The pad was placed securely between the clinician's contact and the donor's neck (33). Three-dimensional (3D) angular displacements of the head relative to the sternum were recorded using an eight-camera optical motion capture system (Motion Analysis, Santa Rosa, CA, USA; $240 \mathrm{~Hz}$ video, $2400 \mathrm{~Hz}$ analogue). All data were time synchronized using a square wave $5 \mathrm{~V}$ electrical pulse at the beginning of each trial. The rising edge of the synchronization pulse was identified in a Matlab script (vR2019b; Mathworks, USA) and designated as time zero across systems. Thereafter, data frames for each system were converted to time in seconds based on the respective sampling frequencies. This approach enabled data extraction across systems at common event timings. Following data collection, Computed Tomography (CT) images of the donor skull to the level of the thoracic spine were acquired (Revolution GSI, GE Healthcare, Chicago, IL, USA).

\section{Data Analysis}

VA lengths acquired with the SonoSoft system were exported to Excel (Microsoft Office 365, Redmond, WA, USA). Intersegmental elongations were summed to give: i) overall VA length change along the entire artery and; ii) VA length change in the V3 segment (Figure 1). VA length change (D) was calculated as:

$D=\left(L_{1}-L_{0}\right) / L_{0}$

where $L_{0}$ was the instantaneous length of the artery at the pre-manipulative position, and $L_{1}$ the instantaneous length of the vessel at the time of peak force during the manipulative thrust. 
Reflective marker positions were tracked using Cortex software (v5.02, Motion Analysis, CA, USA) and filtered using an $8 \mathrm{~Hz}$, low pass, 4 th order zero-lag Butterworth filter in Matlab (34). Orthonormal coordinate systems were defined for the skull and sternum in Matlab using donor-specific 3D bone models created using manual segmentation from the CT images (Mimics, v21, Materialise NV, Belgium). The origin of the skull was located in the centre of the foramen magnum. The origin was defined using the mean coordinates of the mid-points of the lines connecting (1) the left and right inferior lateral, and (2) the anterior and posterior inferior aspects of foramen magnum (Figure 3). The medial-lateral axis was defined in the direction of the inferior lateral aspects of the foramen magnum. The superior-inferior axis was defined using the cross product of the vectors of the medial-lateral and intermediate anterior-posterior axis (i.e. inferior anterior and posterior aspects of foramen magnum). The final anterior-posterior axis was defined as the cross product of the vectors representing the medial-lateral and superior-inferior axes. The origin of the sternum was defined as the mean coordinates of the mid-points of the lines connecting (1) the left and right lateral inferior aspects of the articular facets for the clavicles, and (2) the most superior and inferior aspects of the midline of the sternum. The medial-lateral axis was defined in the direction of the lateral aspects of the sternum. The anterior-posterior axis was defined using the cross product of the vectors of the medial-lateral and intermediate superior-inferior axis (i.e. superior and inferior aspects of the midline). The final superior-inferior axis was defined as the cross product of the vectors representing the medial-lateral and anterior-posterior axes. The coronal axis (X), was defined as positive to the left, the sagittal axis $(Y)$, positive posteriorly, and the transverse axis (Z), positive superiorly (Figure 3 ). Change in head angular displacements relative to the three axes of the sternum LCS were calculated from the time of onset to the time of peak force occurrence during the CSM thrust.

\section{Statistical Analysis}

Descriptive statistics [mean \pm standard deviation (SD), (range)] are used to report the angular displacement of the head relative to the sternum and the VA length changes (whole vessel and V3 segment) during CSM. Differences in VA length changes between adjacent cervical vertebra (i.e. C1 compared to C2 etc.) were calculated using the Wilcoxson Signed Rank Testing Exact method (SPSS, version 27, IBM, USA). Statistical significance was set at $p<0.05$.

\section{Results}

One hundred and sixty-eight CSM were delivered to three male cadaveric donors (88 \pm 6 years old; Table 1 ) in this study, with 165 being used for analysis. There were no significant differences in VA length changes (whole artery or V3 segment) during CSM applied to the different vertebral levels (e.g. C1 vs. C2) (Tables 2 to 4). Therefore, the descriptive statistics were calculated by pooling data from all CSM; i.e. thrusts delivered to each level of the cervical spine (C1 to C7) and on both sides of the neck for all donors and all clinicians (Table 5).

Table 1

- Donor demographics. Abbreviations: male (M); years (yrs); centimeters (cm); kilograms (kg); hours (hr); standard deviation (SD).

\begin{tabular}{|c|c|c|c|c|c|c|c|}
\hline & Sex & $\begin{array}{l}\text { Age } \\
\text { (yrs) }\end{array}$ & $\begin{array}{l}\text { Height } \\
\text { (cm) }\end{array}$ & $\begin{array}{l}\text { Weight } \\
(\mathrm{kg})\end{array}$ & $\begin{array}{l}\text { Time since death } \\
\text { until testing (hr) }\end{array}$ & $\begin{array}{l}\text { Reason for } \\
\text { death }\end{array}$ & Pre-existing conditions \\
\hline & M & 82 & 178 & 71 & 65 & Dementia & Spinal stenosis, Diabetes Mellitus II \\
\hline & M & 94 & 168 & 70 & 144 & $\begin{array}{l}\text { Congestive } \\
\text { cardiac failure }\end{array}$ & Unknown \\
\hline & M & 87 & 170 & 57 & 144 & $\begin{array}{l}\text { Obstructive } \\
\text { pneumonia }\end{array}$ & $\begin{array}{l}\text { Metastatic lung \& colon cancer, chronic obstructive pulmonary } \\
\text { disease, benign prostatic hypertrophy }\end{array}$ \\
\hline $\begin{array}{l}\text { Mean } \\
\pm S D\end{array}$ & & $88 \pm$ & $172 \pm$ & $66 \pm 8$ & $118 \pm 46$ & & \\
\hline
\end{tabular}


Table 2

- Angular displacement (degrees) of the head relative to the sternum and VA length change (\%) combining data from all donors and clinicians during ipsilateral CSM thrusts. Abbreviations: coronal axis $(\mathrm{X})$; sagittal axis $(\mathrm{Y})$; transverse axis $(\mathrm{Z})$; standard deviation (SD); whole (whole VA); and V3 (V3 segment of VA). Note: ipsilateral manipulations involve contralateral head rotation; positive kinematic values indicate flexion, left lateral flexion and left rotation; positive VA length changes indicate

\begin{tabular}{|c|c|c|c|c|c|c|c|c|c|c|c|}
\hline & & \multicolumn{5}{|c|}{ Rotation } & \multicolumn{5}{|c|}{ Lateral flexion } \\
\hline & & $x$ & Y & Z & Whole & V3 & $x$ & Y & Z & Whole & V3 \\
\hline \multirow[t]{4}{*}{$\mathrm{C} 1$} & Mean & 2.5 & 8.1 & -11.5 & 1.1 & 3.7 & -3.0 & 4.9 & -4.4 & 0.9 & 2.6 \\
\hline & SD & 2.6 & 2.8 & 3.8 & 0.9 & 4.4 & 1.7 & 4.3 & 7.8 & 1.5 & 4.3 \\
\hline & Minimum & 0.2 & 5.9 & -15.0 & 0.0 & -0.3 & -5.3 & 0.4 & -20.0 & -1.1 & 0.0 \\
\hline & Maximum & 6.5 & 12.5 & -5.8 & 2.3 & 10.0 & -0.9 & 10.7 & 0.7 & 3.2 & 10.4 \\
\hline \multirow[t]{4}{*}{ C2 } & Mean & 2.1 & 10.0 & -12.6 & 1.6 & -0.1 & -5.3 & 5.6 & -6.4 & 1.1 & 2.3 \\
\hline & SD & 4.4 & 3.5 & 4.5 & 1.3 & 5.3 & 4.2 & 3.2 & 8.9 & 0.8 & 3.6 \\
\hline & Minimum & -3.8 & 5.0 & -16.1 & 0.1 & -9.3 & -13.0 & 1.0 & -19.3 & 0.2 & -0.3 \\
\hline & Maximum & 7.6 & 13.9 & -3.7 & 3.2 & 7.1 & -1.6 & 9.8 & 7.9 & 2.1 & 8.9 \\
\hline \multirow[t]{4}{*}{ C3 } & Mean & -0.3 & 7.2 & -11.0 & 1.9 & 4.5 & -3.6 & 4.7 & -4.1 & 0.7 & 1.7 \\
\hline & SD & 2.1 & 2.3 & 2.6 & 0.7 & 5.4 & 2.2 & 3.2 & 3.0 & 0.5 & 2.6 \\
\hline & Minimum & -1.9 & 4.4 & -13.7 & 0.8 & 0.0 & -7.0 & 1.1 & -8.9 & 0.2 & 0.0 \\
\hline & Maximum & 2.8 & 10.1 & -7.5 & 2.4 & 10.8 & -1.4 & 9.4 & -0.9 & 1.3 & 6.7 \\
\hline \multirow[t]{4}{*}{ C4 } & Mean & 1.5 & 8.9 & -9.8 & 1.4 & 2.8 & -3.9 & 6.3 & -5.1 & 0.6 & 2.1 \\
\hline & SD & 2.6 & 4.5 & 3.7 & 1.0 & 4.0 & 3.1 & 2.5 & 5.1 & 1.0 & 2.6 \\
\hline & Minimum & -2.8 & 2.5 & -14.5 & 0.2 & 0.0 & -9.1 & 2.2 & -10.7 & -0.6 & 0.0 \\
\hline & Maximum & 5.0 & 13.2 & -5.6 & 2.7 & 8.6 & -1.7 & 9.1 & 2.0 & 2.1 & 5.6 \\
\hline \multirow[t]{4}{*}{ C5 } & Mean & 1.4 & 9.6 & -10.7 & 1.8 & 2.5 & -3.9 & 5.7 & -2.1 & 1.2 & 2.5 \\
\hline & SD & 4.7 & 2.7 & 3.1 & 1.2 & 3.1 & 3.0 & 3.8 & 4.2 & 1.0 & 2.6 \\
\hline & Minimum & -6.1 & 5.7 & -15.5 & -0.1 & 0.0 & -7.6 & 1.3 & -6.0 & 0.2 & 0.0 \\
\hline & Maximum & 5.1 & 12.6 & -7.4 & 3.1 & 6.6 & -0.9 & 12.6 & 5.5 & 2.6 & 6.4 \\
\hline \multirow[t]{4}{*}{ C6 } & Mean & 1.3 & 8.9 & -8.0 & 1.0 & 1.8 & -4.2 & 4.6 & -5.4 & 1.3 & 2.4 \\
\hline & SD & 3.2 & 3.0 & 2.6 & 1.2 & 3.7 & 3.2 & 2.0 & 6.3 & 0.7 & 2.4 \\
\hline & Minimum & -3.9 & 5.0 & -12.0 & -0.4 & -0.4 & -9.4 & 1.5 & -10.6 & 0.7 & 0.0 \\
\hline & Maximum & 5.5 & 14.1 & -4.6 & 3.1 & 11.6 & -1.1 & 6.5 & 5.1 & 2.1 & 5.8 \\
\hline \multirow[t]{4}{*}{ C7 } & Mean & -0.8 & 8.7 & -9.5 & 1.3 & 2.0 & -3.5 & 5.4 & -3.3 & 1.2 & 2.0 \\
\hline & SD & 4.3 & 2.6 & 3.0 & 1.1 & 2.8 & 3.5 & 2.6 & 4.1 & 1.0 & 3.6 \\
\hline & Minimum & -6.6 & 6.0 & -15.3 & 0.3 & -0.1 & -8.8 & 2.3 & -7.7 & -0.3 & -1.1 \\
\hline & Maximum & 3.9 & 12.3 & -7.0 & 3.3 & 6.8 & 0.8 & 7.9 & 2.5 & 2.3 & 7.1 \\
\hline
\end{tabular}


Table 3

- Angular displacement (degrees) of the head relative to the sternum and VA length change (\%) combining data from all donors and clinicians during contralateral CSM thrusts. Abbreviations: coronal axis (X); sagittal axis (Y); transverse axis (Z); standard deviation (SD); whole (whole VA); and V3 (V3 segment of VA). Note: contralateral manipulations involve ipsilateral head rotation; positive kinematic values indicate flexion, left lateral flexion and left rotation; positive VA length changes indicate elongation of the vessel.

\begin{tabular}{|c|c|c|c|c|c|c|c|c|c|c|c|}
\hline & & \multicolumn{5}{|c|}{ Rotation } & \multicolumn{5}{|c|}{ Lateral flexion } \\
\hline & & $x$ & $\mathrm{Y}$ & Z & Whole & V3 & $x$ & Y & Z & Whole & V3 \\
\hline \multirow[t]{4}{*}{$\mathrm{C} 1$} & Mean & 1.0 & -8.8 & 9.7 & 0.9 & 1.8 & -2.0 & -5.9 & 0.1 & 0.8 & 1.8 \\
\hline & SD & 3.4 & 2.0 & 3.3 & 0.8 & 1.4 & 1.6 & 3.0 & 4.1 & 1.2 & 1.8 \\
\hline & Minimum & -2.9 & -11.8 & 6.2 & 0.2 & 0.0 & -5.0 & -10.1 & -3.9 & -1.3 & 0.0 \\
\hline & Maximum & 5.2 & -6.5 & 14.6 & 2.2 & 3.1 & -0.5 & -2.8 & 7.6 & 1.9 & 3.7 \\
\hline \multirow[t]{4}{*}{$\mathrm{C} 2$} & Mean & 0.9 & -7.0 & 9.7 & 0.6 & 0.9 & -2.3 & -5.6 & -0.3 & 1.6 & 2.0 \\
\hline & SD & 2.8 & 3.0 & 3.2 & 0.4 & 1.0 & 3.3 & 5.7 & 2.2 & 1.2 & 2.6 \\
\hline & Minimum & -2.6 & -10.3 & 5.4 & 0.2 & 0.0 & -7.3 & -11.5 & -4.0 & 0.1 & 0.0 \\
\hline & Maximum & 4.2 & -2.6 & 13.6 & 1.1 & 2.2 & 1.8 & 4.4 & 2.3 & 3.6 & 6.0 \\
\hline \multirow[t]{4}{*}{ C3 } & Mean & 0.5 & -9.1 & 8.3 & 1.4 & 2.2 & -3.8 & -7.4 & 1.6 & 1.4 & 1.1 \\
\hline & SD & 4.5 & 5.7 & 2.7 & 0.7 & 2.7 & 2.9 & 4.2 & 4.3 & 2.0 & 1.9 \\
\hline & Minimum & -3.6 & -19.3 & 3.9 & 0.2 & 0.0 & -7.1 & -15.1 & -3.1 & -1.4 & -1.3 \\
\hline & Maximum & 9.1 & -3.7 & 11.0 & 2.3 & 5.8 & -0.3 & -4.3 & 8.8 & 4.2 & 4.2 \\
\hline \multirow[t]{4}{*}{$\mathrm{C} 4$} & Mean & 0.1 & -8.2 & 7.4 & 1.0 & 1.3 & -4.3 & -6.0 & 1.8 & 1.8 & 0.7 \\
\hline & SD & 2.0 & 3.9 & 2.5 & 0.7 & 1.8 & 4.5 & 2.3 & 6.8 & 1.7 & 2.1 \\
\hline & Minimum & -2.5 & -14.5 & 5.1 & -0.3 & -0.7 & -10.1 & -10.1 & -7.8 & 0.0 & -1.3 \\
\hline & Maximum & 3.5 & -3.8 & 11.6 & 1.6 & 3.5 & 1.0 & -3.6 & 12.9 & 4.4 & 3.9 \\
\hline \multirow[t]{4}{*}{ C5 } & Mean & -1.3 & -5.4 & 4.5 & 1.1 & 1.0 & -3.7 & -6.3 & 3.6 & 0.9 & 1.8 \\
\hline & SD & 1.0 & 2.6 & 1.9 & 0.6 & 1.3 & 1.7 & 2.6 & 6.1 & 1.7 & 2.4 \\
\hline & Minimum & -3.2 & -8.5 & 2.2 & 0.3 & 0.0 & -6.6 & -9.0 & -2.8 & -2.0 & -0.2 \\
\hline & Maximum & -0.2 & -1.9 & 7.0 & 1.8 & 3.3 & -1.8 & -3.2 & 11.9 & 2.5 & 5.8 \\
\hline \multirow[t]{4}{*}{$\mathrm{C} 6$} & Mean & -0.7 & -8.3 & 7.5 & 1.2 & 1.4 & -4.6 & -5.2 & 0.8 & 1.5 & 1.7 \\
\hline & SD & 3.5 & 1.6 & 2.6 & 0.2 & 1.5 & 2.3 & 3.2 & 6.4 & 0.7 & 2.0 \\
\hline & Minimum & -7.7 & -10.9 & 3.3 & 1.0 & 0.0 & -6.1 & -8.8 & -4.9 & 0.6 & 0.0 \\
\hline & Maximum & 1.7 & -6.3 & 10.4 & 1.5 & 4.0 & -1.2 & -1.3 & 9.9 & 2.3 & 3.9 \\
\hline \multirow[t]{4}{*}{$\mathrm{C7}$} & Mean & -0.3 & -8.4 & 6.1 & 0.9 & 1.3 & -2.8 & -5.7 & 0.7 & 0.7 & 0.5 \\
\hline & SD & 2.7 & 2.4 & 3.1 & 0.5 & 2.4 & 3.1 & 1.5 & 5.8 & 0.7 & 1.1 \\
\hline & Minimum & -4.3 & -12.3 & 2.7 & 0.2 & -1.1 & -6.7 & -7.9 & -6.5 & 0.0 & -0.8 \\
\hline & Maximum & 2.8 & -6.3 & 10.4 & 1.6 & 4.4 & 1.4 & -3.7 & 10.6 & 1.9 & 2.3 \\
\hline
\end{tabular}


Table 4

- Differences in VA length change between adjacent cervical spine levels during

CSM thrusts. Abbreviations: whole (whole VA); and V3 (V3 segment of VA). Note: statistical significance $(\mathrm{p}<0.05)$ was not achieved for any comparison.

\begin{tabular}{|lllll|}
\hline \multicolumn{5}{|c|}{ VA length change during thrust between adjacent cervical spine levels } \\
\hline & Rotation & Lateral flexion & \\
\hline & Whole (p-value) & V3 (p-value) & Whole (p-value) & V3 (p-value) \\
\hline C1 - C2 & 0.850 & 0.055 & 0.339 & 0.945 \\
\hline C2 - C3 & 0.375 & 0.232 & 0.301 & 0.547 \\
\hline C3 - C4 & 0.322 & 0.846 & 0.520 & 0.910 \\
\hline C4 - C5 & 0.365 & 0.910 & 0.898 & 0.203 \\
\hline C5 - C6 & 0.638 & $>0.999$ & 0.164 & 0.641 \\
\hline C6 - C7 & 0.898 & 0.846 & 0.301 & 0.641 \\
\hline C1 - C7 & 0.831 & 0.148 & 0.791 & 0.109 \\
\hline
\end{tabular}

Table 5

- Angular displacement (degrees) of the head relative to the sternum and VA length change (\%) combining data from all cervical spine levels (C1 to C7), don during CSM thrusts. Abbreviations: coronal axis (X); sagittal axis (Y); transverse axis (Z); standard deviation (SD); whole (whole VA); and V3 (V3 segment of V, manipulations involve contralateral head rotation; positive kinematic values indicate flexion, left lateral flexion and left rotation; positive VA length changes inc the vessel.

\begin{tabular}{|c|c|c|c|c|c|c|c|c|c|c|c|c|c|c|c|c|c|c|}
\hline & \multicolumn{10}{|c|}{ Ipsilateral cervical spine manipulation } & \multicolumn{8}{|c|}{ Contralateral cervical spine manipulation } \\
\hline & \multicolumn{5}{|c|}{ Rotation } & \multicolumn{5}{|c|}{ Lateral flexion } & \multicolumn{5}{|c|}{ Rotation } & \multicolumn{3}{|c|}{ Lateral flexion } \\
\hline & $\mathbf{x}$ & $\mathbf{Y}$ & $\mathbf{Z}$ & Whole & V3 & $x$ & $\mathbf{Y}$ & Z & Whole & V3 & $\mathbf{x}$ & $\mathbf{Y}$ & $\mathbf{Z}$ & Whole & V3 & $\mathbf{x}$ & $\mathbf{Y}$ & Z \\
\hline Mean & 1.2 & 8.8 & -10.2 & 1.3 & 2.6 & -3.9 & 5.3 & -4.4 & 1.0 & 2.2 & 0.0 & -7.9 & 7.7 & 1.0 & 1.4 & -3.3 & -6.1 & 1.2 \\
\hline SD & 3.4 & 3.0 & 3.5 & 1.0 & 3.6 & 2.9 & 3.0 & 5.7 & 0.9 & 3.0 & 2.9 & 3.3 & 3.1 & 0.6 & 1.7 & 2.9 & 3.2 & 5.0 \\
\hline Minimum & -6.6 & 2.5 & -16.1 & -0.4 & -0.4 & -13.0 & 0.4 & -20.0 & -1.1 & -1.1 & -7.7 & -19.3 & 2.2 & -0.3 & -1.1 & -10.1 & -15.1 & $-7 . \varepsilon$ \\
\hline Maximum & 7.6 & 14.1 & -3.7 & 3.3 & 11.6 & 0.8 & 12.6 & 7.9 & 3.2 & 10.4 & 9.1 & -1.9 & 14.6 & 2.3 & 5.8 & 1.8 & 4.4 & 12. \\
\hline
\end{tabular}

\section{Ipsilateral CSM: Rotation (involving contralateral head rotation)}

VA length changes during CSM thrusts were greatest with ipsilateral rotation thrusts for the whole artery [mean \pm SD, (range)] $1.3 \pm 1.0 \%,(-0.4$ to $3.3 \%)$ and the V3 segment $2.6 \pm 3.6 \%$, (-0.4 to $11.6 \%)$. Head motion relative to the sternum during the CSM thrust phase was in axial rotation (Z) $-10.2 \pm 3.5^{\circ}$, $\left(-16.1\right.$ to $\left.-3.7^{\circ}\right)$, lateral flexion $(Y) 8.8 \pm 3.0^{\circ},\left(2.5\right.$ to $\left.14.1^{\circ}\right)$ and variable flexion or extension $(X) 1.2 \pm 3.4^{\circ},\left(-6.6\right.$ to $\left.7.6^{\circ}\right)$ (Table 5$)$.

\section{Ipsilateral CSM: Lateral flexion (involving contralateral head rotation)}

During ipsilateral lateral flexion thrusts, VA length changes were similar to those seen with ipsilateral rotation thrusts for both the whole artery [mean \pm SD, (range)] $1.0 \pm 0.9 \%,(-1.1$ to $3.2 \%)$ and V3 segment $2.2 \pm 3.0 \%,(-1.1$ to $10.4 \%)$. Head motion relative to the sternum during the CSM thrust phase was in lateral flexion $(Y) 5.3 \pm 3.0^{\circ},\left(0.4\right.$ to $\left.12.6^{\circ}\right)$, variable axial rotation $(Z)-4.4 \pm 5.7^{\circ},\left(-20.0\right.$ to $\left.7.9^{\circ}\right)$ and variable extension or flexion $(X)-3.9 \pm 2.9^{\circ},\left(-13.0\right.$ to $\left.0.8^{\circ}\right)($ Table 5).

\section{Contralateral CSM: Rotation (involving ipsilateral head rotation)}

During contralateral rotation thrusts, VA length changes were for the whole artery [mean \pm SD, (range)] $1.0 \pm 0.6 \%$, (-0.3 to $2.3 \%)$ and $\mathrm{V} 3$ segment $1.4 \pm 1.7 \%$, $(-1.1$ to $5.8 \%)$. Head motion relative to the sternum during the CSM thrust phase was in lateral flexion $(\mathrm{Y})-7.9 \pm 3.3^{\circ},\left(-19.3\right.$ to $\left.-1.9^{\circ}\right)$, axial rotation $(\mathrm{Z}) 7.7 \pm$ $3.1^{\circ},\left(2.2\right.$ to $\left.14.6^{\circ}\right)$ and variable flexion or extension $(X) 0.0 \pm 2.9^{\circ},\left(-7.7\right.$ to $\left.9.1^{\circ}\right)$ (Table 5$)$.

\section{Contralateral CSM: Lateral flexion (involving ipsilateral head rotation)}

During contralateral lateral flexion thrusts, VA length changes were slightly greater than those seen with rotation for the whole artery [mean \pm SD, (range)] $1.2 \pm$ $1.4 \%,(-2.0$ to $4.4 \%)$ and the V3 segment $1.4 \pm 2.0 \%$, (-1.3 to $6.0 \%)$. Head motion relative to the sternum during the CSM thrust phase was in variable lateral flexion $(\mathrm{Y})-6.1 \pm 3.2^{\circ},\left(-15.1\right.$ to $\left.4.4^{\circ}\right)$, variable extension or flexion $(\mathrm{X})-3.3 \pm 2.9^{\circ},\left(-10.1\right.$ to $\left.1.8^{\circ}\right)$ and variable axial rotation $(\mathrm{Z}) 1.2 \pm 5.0^{\circ},\left(-7.8\right.$ to $\left.12.9^{\circ}\right)(\mathrm{Table}$ 5).

\section{Discussion}

The purpose of this study was to quantify the angular displacements of the head relative to the sternum and the associated VA length changes during the thrust phase of two types of CSM (rotation and lateral flexion), applied bilaterally, to each level of the cervical spine (C1 to C7). The primary result of this study was that irrespective of the type of CSM, the side or level of CSM application, angular displacements of the head and associated VA length changes were small (Tables 2, 3 \& 5) compared to those occurring at peak CSM force occurrence in the only other study to measure these two parameters simultaneously 
(26). Additionally, there was considerable variability in the length changes measured in the whole artery and V3 segment across different specimens and clinicians (Tables 2, 3 \& 5).

The current results report similar amounts of flexion, lateral flexion and axial rotation during the manipulative thrust as reported previously, despite methodological differences in the CSM technique used and vertebral level contacted $(20,22-25,35)($ Tables $2,3 \& 5)$. Additionally, there did not appear to be a relationship between the vertebra to which the thrust was applied and the change in angular displacement of the head relative to the sternum during the thrust $(21,35)$. Likewise, there were no significant differences in VA length changes when CSM thrusts were applied to the different vertebral levels (Table 4).

However, as the angular displacement of the head relative to the sternum was quantified, and VA length changes were measured for the entire VA and the V3 segment, it is possible that there are differences in the segmental motion and intersegmental VA length changes between adjacent cervical vertebrae. Supporting this argument for differences in segmental vs. global kinematics, it has been reported that angular displacements of individual cervical vertebrae in sagittal plane flexion/extension of the head may be greater at intermediate head flexion/extension angles than at maximal head flexion/extension angles

(36). Additionally, VA length changes were observed in opposite directions in adjacent motion segments i.e. elongation at the C1/2 level and shortening at the C2/3 level, consistent with one previous report (28).

An important consideration for the clinician may be that head movements in different directions were associated with different length changes of the VA (e.g. ipsilateral lateral flexion typically resulted in shortening of the VA while contralateral lateral flexion and rotation to either side resulted in elongation of the VA). CSM involving contralateral head rotation, on average, resulted in greater VA length changes than CSM involving ipsilateral head rotation, highlighting a possible relationship between rotational kinematics and VA length change (Tables $2 \& 5$ ). This finding of greater VA length change with contralateral head rotation is consistent with findings in the literature (26-29).

Another consideration is that despite considerable variability, there was, on average, an elongation of the V3 segment - irrespective of the vertebra targeted by the CSM (Tables 2, 3 \& 5). This finding may be important as VA dissections occur more frequently in the V3 segment than in other areas of the VA (17-19). However, it should be noted that even though the V3 segment usually elongated during CSM, there were instances when a shortening of the V3 segment was observed (maximum of -9.3\%) (Table 2). This highlights possible biomechanical differences in VA response between individuals receiving CSM. Visual inspection of the data did not reveal any patterns regarding VA response between cadavers or practitioners, thus it is unknown exactly what causes this variability but it is possible that anatomic differences in the course of the vessel (thus reducing the length of the V3 segment) (18) and/or variable CSM thrust delivery by different practitioners (37) may be important factors. Variability in the length changes associated with CSM has been reported previously (26-29). However, there does not appear to be a qualitative difference in the variability of VA length changes between the lateral flexion and rotation CSM delivered in this study.

It is also important to contextualize these results using the knowledge that whole VA must elongate on average $33.5 \%$ from an arbitrary in-situ position of the head/neck (30) and about $12 \%$ when measured from a standardized neutral anatomical position (29) prior to experiencing tensile stretch. As the largest whole artery elongation measured during the thrust phase was $4.4 \%$ in this study, it is possible that none of the CSM reported here resulted in tensile stretch of the VA. However, the current study used an arbitrary in-situ position (head on the gurney) as the reference configuration as opposed to the standardized neutral anatomical head and neck position used in previous studies (26-29). Also, the head position prior to manipulation could likely differ from one CSM thrust to the next, between clinicians, and for the different ( $\mathrm{C} 1$ to $\mathrm{C} 7$ ) treatment levels. Thus, to unequivocally answer the question if CSM results in tensile stretch of the VA, these results should be replicated using a defined in-situ head/neck position.

\section{Limitations}

This study involved cadaveric donors where dissection artifacts were unavoidable. While every effort was made to minimize alteration of tissues, dissection artifacts may have contributed to the mechanics of CSM and head motion that may not directly generalize to the clinical setting. Specifically, there could be differences in load transfer from the practitioner to the cadaver compared to from the practitioner to a live patient, due to the removal of soft tissues which could result in increased magnitudes of head displacements during CSM delivered to cadaveric donors. Thus, it is possible that with the removal of soft tissues, VA length changes may have been overestimated here compared to those occurring in a clinical situation.

Secondly, in patients, the VA experiences not only longitudinal (measured in our study) but also pulsatile circumferential and radial strains due to blood pressure. We made no attempt to pressurize the artery (to mimic radial strains) and did not measure either circumferential or radial strains. Further, no attempt was made to differentiate length changes within the three separate layers of the vessel wall. However, as longitudinal length changes have been implicated primarily as the cause of VA injury, and the current methods likely approximate these length changes, we are confident that we closely represent longitudinal length changes occurring in-vivo during CSM (38).

Another limitation of this study is that VA length changes were measured only for the thrust phase of CSM, no standardized reference length for comparison with literature values of VA length changes occurring at the time of peak force occurrence were available. In other words, a VA length change of $3 \%$ measured in this study, could be a length change from $94-97 \%$ of the reference length (100\%) from a standardized neutral anatomical head and neck configuration (2629 ), or it could be from $107-110 \%$, or from $123-126 \%$. The absence of a standardized reference configuration, thus, does not allow for statements regarding the potential damage of the VA due to over-stretching.

\section{Conclusions}

Head angular displacements and VA length changes were small during CSM thrusts. Of the four CSM procedures measured, mean VA length changes were largest during rotation procedures. This suggests that if clinicians wish to limit VA length changes during CSM, consideration should be given to the type of

Page $8 / 12$ 


\section{Declarations}

\section{Ethics approval and consent to participate}

The study was approved by the Conjoint Health Research Ethics Board (REB16-0296) of the University of Calgary.

\section{Consent for publication}

Not applicable.

\section{Availability of data and materials}

The datasets used and/or analysed during the current study are available from the corresponding author on reasonable request.

\section{Competing interests}

The authors declare no competing interests.

\section{Funding}

The authors would like to thank the funding sources, The Canadian Chiropractic Research Foundation and the Alberta College and Association of Chiropractors.

\section{Authors' contributions}

LG: Conceptualization, Methodology, Data Collection, Data Analysis, Investigation, Writing - Original Draft. GK: Data Collection, Data Analysis, Investigation, Writing - Review and Editing. JR: Resources, Data Analysis, Writing - Review and Editing. JT: Data Analysis, Writing - Review and Editing. RC \& BS: Data Collection. WH: Conceptualization, Methodology, Resources, Writing - Review and Editing.

\section{Acknowledgements}

Additionally, the authors would like to thank the donors and staff at The University of Calgary Body Donation Program and support staff - Mr. Andrew Sawatsky and Mr. Hoa Nguyen and Drs. Tim Leonard and Seong-won Han.

\section{References}

1. Martin BI, Deyo RA, Mirza SK, et al. Expenditures and health status among adults with back and neck problems. J Am Med Assoc. 2008;299(6):65664.

2. James SL, Abate D, Abate KH, Abay SM, Abbafati C, Abbasi N, et al. Global, regional, and national incidence, prevalence, and years lived with disability for 354 diseases and injuries for 195 countries and territories, 1990-2017: a systematic analysis for the global burden of disease study 2017 . The Lancet. 2018 Nov 10;392(10159):1789-858.

3. Fejer R, Kyvik KO, Hartvigsen J. The prevalence of neck pain in the world population: a systematic critical review of the literature. Eur Spine J. 2006 Jun;15(6):834-48.

4. Bryans R, Decina P, Descarreaux M, Duranleau M, Marcoux H, Potter B, et al. Evidence-based guidelines for the chiropractic treatment of adults with neck pain. J Manipulative Physiol Ther. 2014 Jan;37(1):42-63.

5. Hurwitz EL, Carragee EJ, van der Velde G, Carroll LJ, Nordin M, Guzman J, et al. Treatment of neck pain: noninvasive interventions: results of the bone and joint decade 2000-2010 task force on neck pain and its associated disorders. Eur Spine J. 2008 04;17(Suppl 1):123-52.

6. Bussieres AE, Stewart G, Al-Zoubi F, Decina P, Descarreaux M, Hayden J, et al. The treatment of neck pain-associated disorders and whiplash-associated disorders: a clinical practice guideline. J Manipulative Physiol Ther. 2016 Oct;39(8):523-64.

7. Bier JD, Scholten-Peeters WGM, Staal JB, Pool J, van Tulder MW, Beekman E, et al. Clinical practice guideline for physical therapy assessment and treatment in patients with nonspecific neck pain. Phys Ther. 2018 Mar 1;98(3):162-71. 
8. Whalen W, Farabaugh RJ, Hawk C, Minkalis AL, Lauretti W, Crivelli LS, et al. Best-practice recommendations for chiropractic management of patients with neck pain. J Manipulative Physiol Ther. 2019 Nov 1;42(9):635-50.

9. Bronfort G, Haas M, Evans R, Leininger B, Triano J. Effectiveness of manual therapies: the UK evidence report. Chiropr Osteopat. 2010;18(1):3.

10. Gross A, Miller J, D'Sylva J, Burnie S, Goldsmith C, Graham N, et al. Manipulation or mobilisation for neck pain: a cochrane review. Man Ther. 2010 Aug;15(4):315-33.

11. Puentedura EJ, March J, Anders J, Perez A, Landers MR, Wallmann HW, et al. Safety of cervical spine manipulation: are adverse events preventable and are manipulations being performed appropriately? A review of 134 case reports. J Man Manip Ther. 2012 May;20(2):66-74.

12. Di Fabio RP. Manipulation of the cervical spine: risks and benefits. Phys Ther. 1999 Jan;79(1):50-65.

13. Biller J, Sacco RL, Albuquerque FC, Demaerschalk BM, Fayad P, Long PH, et al. Cervical arterial dissections and association with cervical manipulative therapy: a statement for healthcare professionals from the american heart association/american stroke association. Stroke J Cereb Circ. 2014 Oct; $45(10): 3155-74$.

14. Ernst E. Adverse effects of spinal manipulation: a systematic review. J R Soc Med. 2007 Jul;100(7):330-8.

15. Frisoni GB, Anzola GP. Vertebrobasilar ischemia after neck motion. Stroke. 1991 Nov;22:1452-60.

16. Assendelft WJ, Bouter LM, Knipschild PG. Complications of spinal manipulation: a comprehensive review of the literature. J Fam Pract. 1996 May;42(5):475-80.

17. Haldeman S, Kohlbeck FJ, McGregor M. Stroke, cerebral artery dissection, and cervical spine manipulation therapy. J Neurol. 2002 Aug;249(8):1098104.

18. Mann T, Refshauge KM. Causes of complications from cervical spine manipulation. Aust J Physiother. 2001 Jan 1;47(4):255-66.

19. Mitchell J. Vertebral artery blood flow velocity changes associated with cervical spine rotation: a meta-analysis of the evidence with implications for professional practice. J Man Manip Ther. 2009;17(1):46-57.

20. Triano JJ, Schultz AB. Motions of the head and thorax during neck manipulations. J Manipulative Physiol Ther. 1994 Dec;17(9):573-83.

21. Klein P, Broers C, Feipel V, Salvia P, Van Geyt B, Dugailly PM, et al. Global 3D head-trunk kinematics during cervical spine manipulation at different levels. Clin Biomech. 2003 Nov;18(9):827-31.

22. Ngan JMW, Chow DHK, Holmes AD. The kinematics and intra- and inter-therapist consistencies of lower cervical rotational manipulation. Med Eng Phys. 2005;27(5):395-401.

23. Williams JM, Cuesta-Vargas Al. An investigation into the kinematics of 2 cervical manipulation techniques. J Manipulative Physiol Ther. 2013 Jan $1 ; 36(1): 20-6$.

24. Liguo Z, Minshan F, Xunlu Y, Shangquan W, Jie Y. Kinematics analysis of cervical rotation-traction manipulation measured by a motion capture system. Vemulpad S, editor. Evid Based Complement Alternat Med. 2017 Oct 11;2017:5293916.

25. Dugailly P-M, Beyer B, Sobczak S, Salvia P, Feipel V. Global and regional kinematics of the cervical spine during upper cervical spine manipulation: a reliability analysis of 3D motion data. Man Ther. 2014 Oct;19(5):472-7.

26. Piper SL, Howarth SJ, Triano J, Herzog W. Quantifying strain in the vertebral artery with simultaneous motion analysis of the head and neck: a preliminary investigation. Clin Biomech. 2014 Dec;29(10):1099-107.

27. Symons BP, Leonard T, Herzog W. Internal forces sustained by the vertebral artery during spinal manipulative therapy. J Manipulative Physiol Ther. 2002 Oct;25(8):504-10.

28. Wuest S, Symons B, Leonard T, Herzog W. Preliminary report: biomechanics of vertebral artery segments C1-C6 during cervical spinal manipulation. J Manipulative Physiol Ther. 2010 May;33(4):273-8.

29. Herzog W, Leonard TR, Symons B, Tang C, Wuest S. Vertebral artery strains during high-speed, low amplitude cervical spinal manipulation. J Electromyogr Kinesiol. 2012 Oct;22(5):740-6.

30. Gorrell LM, Sawatsky A, Edwards WB, Herzog W. Vertebral artery strains during cervical spine manipulation and mechanical failure testing - is cervical spine manipulation safe? Prep. In prep;

31. Sugimoto T, Ochi K, Hosomi N, Mukai T, Ueno H, Takahashi T, et al. Ultrasonographic Reference Sizes of the Median and Ulnar Nerves and the Cervical Nerve Roots in Healthy Japanese Adults. Ultrasound Med Biol. 2013 Sep 1;39(9):1560-70.

32. Esposito S, Philipson S, Downie A. Spinal Adjustment Technique: The Chiropractic Art. 1st ed. Craft Printing P/L, Australia; 2005. 
34. Schreven S, Beek PJ, Smeets JBJ. Optimising filtering parameters for a 3D motion analysis system. J Electromyogr Kinesiol. 2015 Oct 1;25(5):808-14.

35. Van Geyt B, Dugailly P-M, Klein P, Lepers Y, Beyer B, Feipel V. Assessment of in vivo 3D kinematics of cervical spine manipulation: Influence of practitioner experience and occurrence of cavitation noise. Musculoskelet Sci Pract. 2017 Apr;28:18-24.

36. Van Mameren H, Drukker J, Sanches H, Beursgens J. Cervical spine motion in the sagittal plane (I) range of motion of actually performed movements, an X-ray cinematographic study. Eur J Morphol. 1990;28(1):47-68.

37. Herzog W. The biomechanics of spinal manipulation. J Bodyw Mov Ther. 2010 Jul;14(3):280-6.

38. Johnson CP, How T, Scraggs M, West CR, Burns J. A biomechanical study of the human vertebral artery with implications for fatal arterial injury. Forensic Sci Int. 2000 Apr 10;109(3):169-82.

\section{Figures}

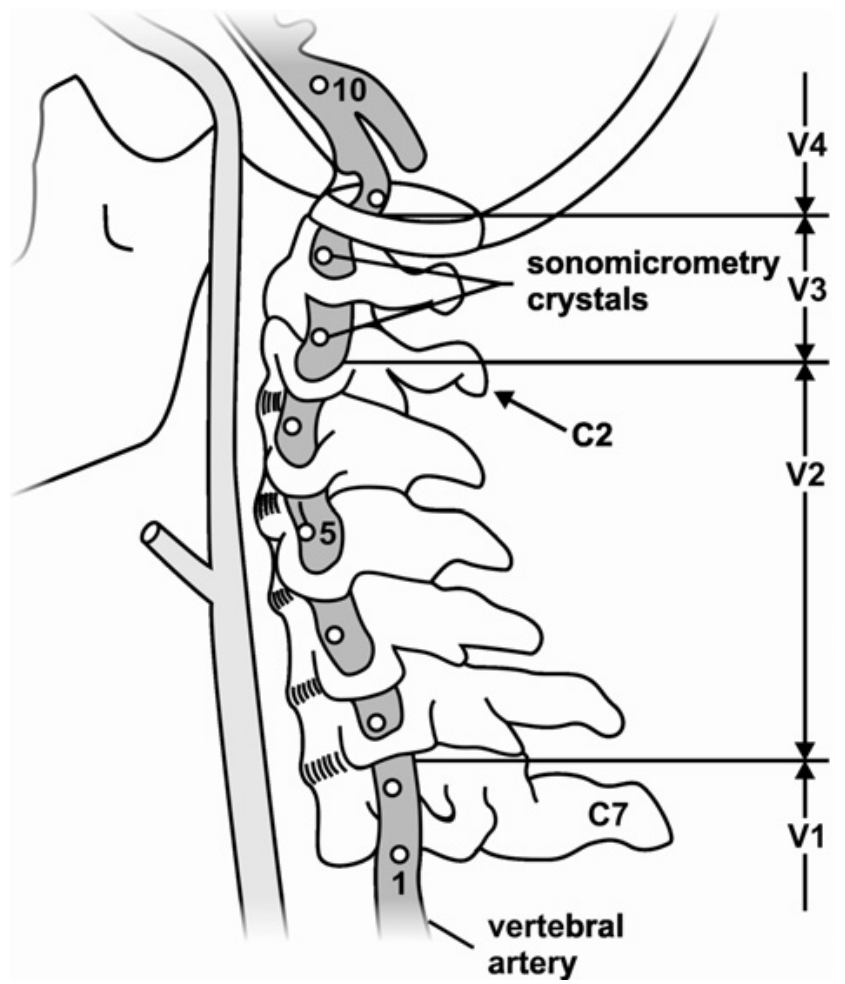

Figure 1

Schematic of ultrasound crystal placement, adapted from Wuest et al. (28). Legend: cervical vertebra (C); vertebral artery region (V); ultrasound crystals (numbers 1-8). 


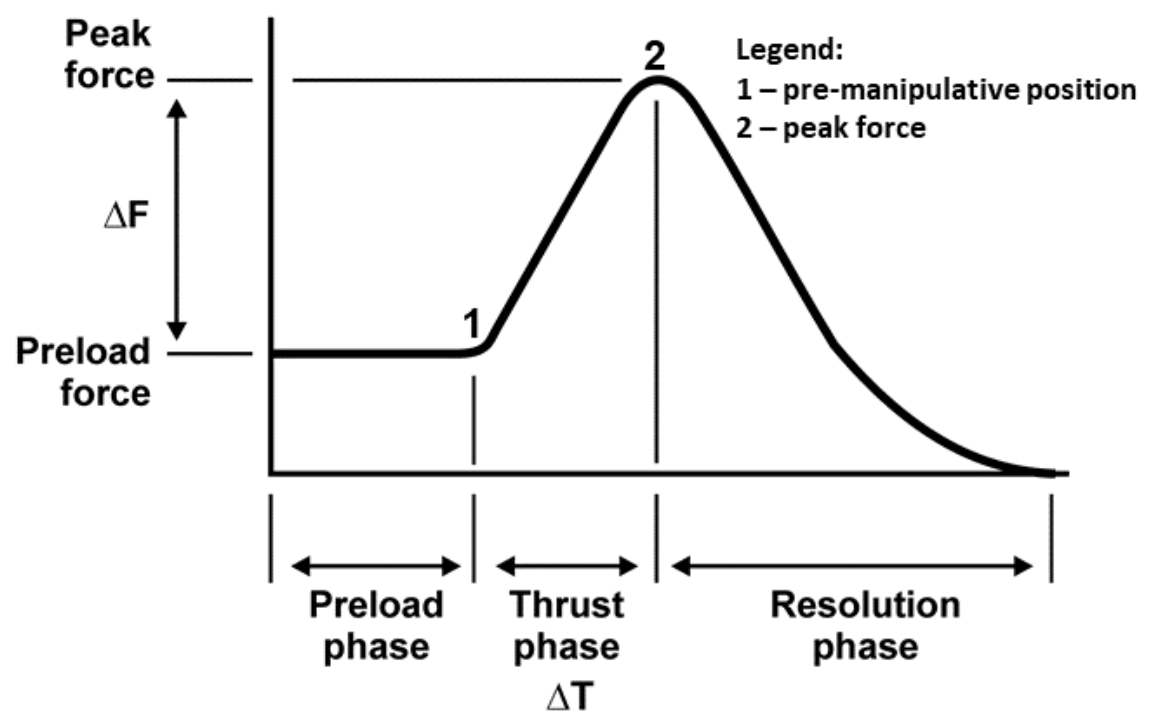

Figure 2

Typical force-time profile for spinal manipulation. Legend: change in $(\Delta)$; force $(F)$, time $(T)$.
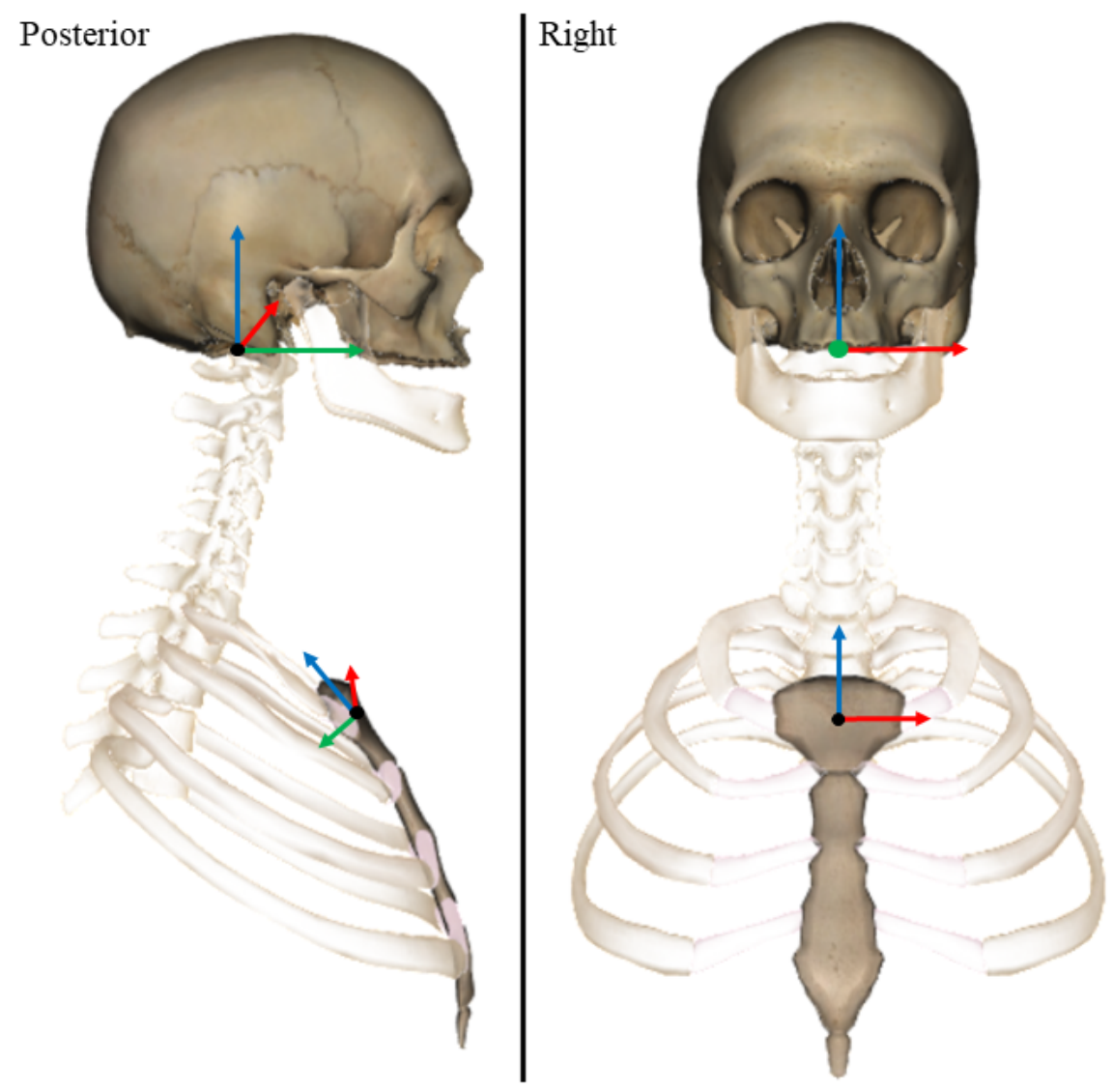

Figure 3

Origins and orthonormal local co-ordinate systems for the skull and sternum: $\mathrm{X}$ axis - segmental flexion/extension (red); $Y$ axis - segmental lateral flexion (green) and; Z axis - axial rotation (blue). 